\title{
Recursos didácticos digitales de la Guerra Civil Española para Bachillerato: análisis de contenido
}

Recibido: 29 de junio de 2018 / Revisado: 15 de julio de 2018

Aceptado: 9 de septiembre de 2018 / Publicado: 19 de diciembre de 2018

\author{
ANGUITA ORTEGA, ÁlVARO \\ Universidad de Granada, España \\ aanguitaortega@correo.ugr.es
}

\section{RESUMEN}

Esta investigación propone un instrumento para analizar el contenido de los recursos didácticos digitales para impartir la Guerra Civil Española en Bachillerato. Para ello, se ha procedido a la lectura crítica de fuentes secundarias y diarios "online", la búsqueda en Internet (webs institucionales, blogs, diarios...) de un recurso didáctico digital de la Guerra Civil, atendiendo a su adecuación al currículo educativo del Bachillerato andaluz, que será analizado y con el que se comprobará la validez del instrumento elaborado siguiendo una metodología de análisis de contenido cualitativa y la lectura del Real Decreto 1105/2014, de 26 de diciembre, del Gobierno de España y la Orden de 14 de julio de 2016 de la Junta de Andalucía (que regulan el currículo del Bachillerato andaluz). Por último, se ha elaborado, teniendo en cuenta las dificultades asociadas al análisis del contenido de estos recursos didácticos, un instrumento para analizar dicho contenido en función de once parámetros que serán expuestos en este artículo. Dicho instrumento ha sido también aplicado al recurso didáctico seleccionado en este trabajo para comprobar su validez.
ABSTRACT

Digital didactic resources of the Spanish Civil War for Baccalaureate: content analysis

This research proposes an instrument to analyze the content of digital didactic resources to impart the Spanish Civil War in Baccalaureate. To this end, the researcher has proceeded to the critical reading of secondary sources and online newspapers, the search on the Internet (institutional websites, blogs, newspapers...) of a digital educational resource of the Civil War, based on its adaptation to the curriculum of the Andalusian Baccalaureate, which will be analyzed and with which the validity of the elaborated instrument will be verified following a qualitative content analysis methodology and the reading of Royal Decree $1105 / 2014$, of December 26, of the Government of Spain and the Order of July 14, 2016 of the Andalusian Regional Executive (which regulate the curriculum of the Andalusian Baccalaureate). Finally, it has been developed, considering the difficulties associated with the analysis of the content of these didactic resources, an instrument to analyze this content based on eleven 
Por otro lado, el análisis de las características y utilidades curriculares del recurso didáctico seleccionado (la web de exhumaciones de fosas comunes de la Asociación para la Recuperación de la Memoria Histórica) ha demostrado que dicho recurso cumple varias funciones curriculares útiles para la enseñanza de la Guerra Civil en Bachillerato. Además, la aplicación del instrumento elaborado a dicho recurso demuestra la validez de este instrumento para analizar el contenido de los recursos didácticos de la Guerra Civil, debiendo tenerse en cuenta que la aplicación de un determinado recurso en el aula no debe atender tanto a su neutralidad como a su rigor a la hora de abordar la Guerra Civil.

Palabras Clave: Bachillerato, Historia Contemporánea, Materiales Educativos, Ideología. parameters that will be presented in this paper. This instrument has also been applied to the didactic resource selected in this research to verify its validity.

Besides, the analysis of the characteristics and curricular utilities of the selected didactic resource (the web of exhumations of mass graves of the Association for the Recovery of the Historical Memory) has demonstrated that this resource fulfills several useful curricular functions for the teaching of the Civil War in Baccalaureate. In addition, the application of the developed instrument to this resource demonstrates the validity of this instrument to analyze the content of the didactic resources of the Civil War, considering that the application of a particular resource in the classroom should not attend to its neutrality but to its rigor when treating the Civil War.

Keywords: Bachelors Degrees, Modern History, Instructional Materials, Ideology.

\section{Introducción}

La Guerra Civil Española (1936-1939) es un tema de fundamental importancia para la Historia de España, por lo que su abordaje en el aula es imprescindible. Sin embargo, se trata también de un período histórico que sigue generando polémica en la actualidad. Debido a este carácter polémico, el docente, a la hora de escoger los recursos didácticos que usará para su enseñanza, debe tener en cuenta el posicionamiento ideológico que cada recurso ofrece sobre la Guerra Civil. La presente investigación se centra en la enseñanza de la Guerra Civil en Bachillerato, pues es en esta etapa educativa (regulada, a nivel andaluz, por el Real Decreto 1105/2014, de 26 de diciembre, del Gobierno de España y la Orden de 14 de julio de 2016 de la Junta de Andalucía) donde hay una mayor presencia de la Guerra Civil, y los recursos didácticos digitales, para atender a la cada vez mayor importancia del adecuado uso de las Tecnologías de la Información y la Comunicación en la educación (Sánchez, Ruiz \& Gómez, 2016: 11-12; 23-24).

Los recursos didácticos sobre la Guerra Civil han sido abordados por varios autores, entre los que cabe mencionar a Maria Feliu Torruella y Francesc Xavier Hernàndez Cardona, que afirman la existencia de una gran variedad de recursos didácticos sobre la Guerra Civil (testimonios de testigos, análisis de lugares de represión, estudio de campos de batalla...) (Feliu \& Hernàndez, 2013: 14-21), o Aritza 
Saenz del Castillo Velasco, que destaca la importancia de la arqueología del conflicto como recurso didáctico de la Guerra Civil, ofreciendo conocimientos sobre la microhistoria que ayudan a comprender la realidad más cotidiana, obviada con frecuencia por los relatos historiográficos positivistas (Feliu \& Hernàndez, 2013: 14-21; Saenz del Castillo, 2015).

No obstante, no hay autores que aborden el tratamiento ideológico que los recursos didácticos de la Guerra Civil ofrecen sobre la misma. Tampoco existen métodos para analizar dicho tratamiento ideológico. Por ejemplo, el Gráfico de Nolan (diagrama político, elaborado en 1969, que define la posición política de una persona atendiendo a su opinión sobre temas económicos y sociales) (Antena 3, 19 de junio 2018) no puede aplicarse a recursos didácticos y las rúbricas (documentos que describen los criterios seguidos para evaluar una tarea o un producto) (García-Barrera, 2016), aunque pueden aplicarse a recursos didácticos, no abordan el posicionamiento ideológico de los mismos.

Teniendo en cuenta lo anterior, el objetivo general de esta investigación es la elaboración de un instrumento que permita analizar el contenido de un recurso didáctico concreto para la enseñanza de la Guerra Civil en Bachillerato. ¿Es válido el instrumento de análisis elaborado? ¿El hecho de que un recurso no sea totalmente neutral en su tratamiento de la Guerra Civil hace poco recomendable su uso en el aula? Esta investigación también responderá a dichas preguntas.

Por otro lado, en cuanto a los objetivos específicos de esta investigación, hay que destacar, en primer lugar, el de analizar las principales características, carencias y utilidades curriculares de la web de exhumaciones de fosas comunes de la Asociación para la Recuperación de la Memoria Histórica, recurso didáctico digital seleccionado por su adecuación al currículo educativo andaluz de Bachillerato para comprobar, con él, la validez del instrumento elaborado. De este objetivo específico surge otra pregunta que será respondida por la investigación: ¿Es realmente útil este recurso en relación con el currículo educativo del Bachillerato andaluz? Los otros dos objetivos específicos del presente trabajo son analizar el modelo de profesionalidad docente y el potencial para el desarrollo profesional del profesorado que ofrece el recurso didáctico seleccionado en esta investigación y comprobar si dicho recurso propicia un aprendizaje significativo y adaptado a las posibilidades e intereses del alumnado.

\section{Material y método}

En cuanto al material usado para la elaboración de este trabajo, se ha procedido a la lectura crítica de fuentes secundarias (publicaciones de autores como Aritza Saenz del Castillo Velasco, que aborda la utilidad de la arqueología del conflicto como recurso didáctico de la Guerra Civil Española, o Alba García-Barrera, que reflexiona acerca de las utilidades y carencias de las rúbricas, y libros de reconocidos autores en el ámbito de los recursos didácticos sobre la Guerra Civil, como Maria Feliu Torruella y 
Francisco Xavier Hernàndez Cardona) y diarios “online" (Huffington Post y El País) para la búsqueda de información. Además, se ha recurrido a Internet (diarios y revistas "online", blogs, webs institucionales como la de la Asociación para la Recuperación de la Memoria Histórica...) para llevar a cabo la búsqueda de un recurso didáctico digital sobre la Guerra Civil y de rúbricas aplicables a recursos didácticos. También se ha leído minuciosa y críticamente la legislación oficial que rige el currículo educativo del Bachillerato andaluz (el Real Decreto 1105/2014, de 26 de diciembre, del Gobierno de España y la Orden de 14 de julio de 2016 de la Junta de Andalucía) para analizar la presencia de la Guerra Civil en el mismo y la utilidad curricular del recurso seleccionado.

Por otro lado, en lo que respecta a la metodología seguida para llevar a cabo esta investigación, se ha procedido a un análisis de contenido de carácter cualitativo, cuya necesidad en dicha investigación se justifica, en primer lugar, por la importancia de interpretar y comprender las principales características, carencias y utilidades curriculares del recurso didáctico de la Guerra Civil seleccionado en este trabajo. Además, se ha elaborado, teniendo en cuenta las dificultades de analizar el contenido de los recursos didácticos digitales de la Guerra Civil, un instrumento para analizarlo basado en once parámetros: mayor o menor presencia de recursos de uno y otro bando, posicionamiento ideológico de la fuente que aporta el recurso, justificación del propio recurso, uso del lenguaje efectuado por el recurso, realización o no de apologías de uno u otro bando por el recurso, mayor o menor uso de imágenes de uno u otro bando, personalidades de uno u otro bando mencionadas por el recurso, posible aparición de logos o símbolos de uno u otro bando en el recurso, posicionamiento ideológico del recurso con respecto a la Guerra Civil, potencialidad del recurso para propiciar la reflexión curricular en el aula e implicaciones del recurso para la profesionalidad docente. Dicho instrumento ha sido también aplicado al recurso didáctico seleccionado en este trabajo para verificar su validez, siguiéndose también para ello una metodología de análisis de contenido de carácter cualitativo con el objetivo de interpretar la información asociada a cada uno de los parámetros anteriormente expuestos.

\section{Resultados}

\section{1. Un recurso didáctico digital de la Guerra Civil: la web de exhumaciones de fosas comunes de la Asociación para la Recuperación de la Memoria Histórica}

En este subapartado, se analizarán las principales características del recurso didáctico digital de la Guerra Civil seleccionado para comprobar la validez del instrumento propuesto en este trabajo para analizar el contenido del mismo: la web de exhumaciones de fosas comunes de la Asociación para la Recuperación de la Memoria Histórica. Además, se expondrán las carencias y utilidades curriculares de dicho recurso en relación al currículo educativo del Bachillerato andaluz.

$4 \cdot$ International Journal of New Education | $N^{0} 2$ 
La Memoria Histórica de la Guerra Civil es un problema que llega hasta la actualidad, apareciendo como uno de los grandes temas de debate en la sociedad española (Rengel, 27 de diciembre 2017). Por tanto, su estudio en las aulas de Bachillerato resulta indispensable a la hora de abordar la Guerra Civil.

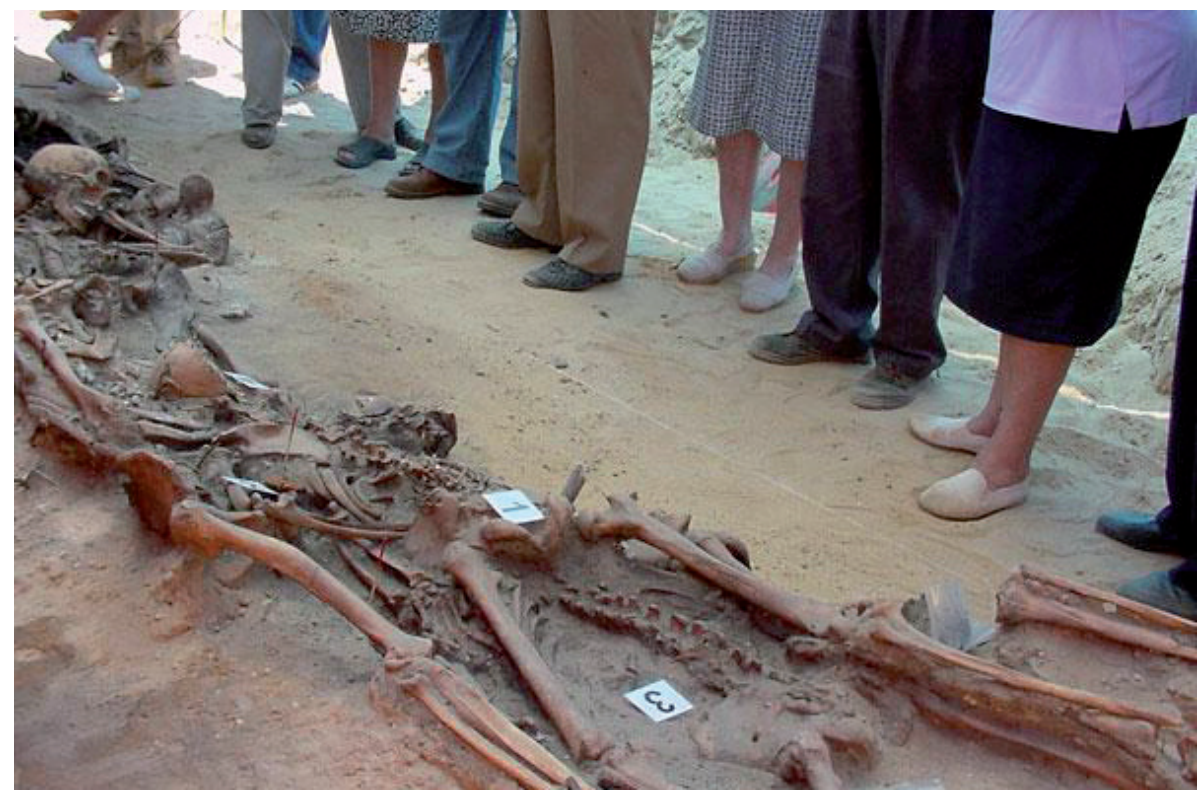

Fotografía 1. Restos de una fosa común de la Guerra Civil. Fuente: Sociedad de Ciencias Aranzadi, s. f. (recuperado de: http://www.aranzadi.eus/antropologia-fisica/memoria-historica).

La web de exhumaciones de fosas comunes de la Asociación para la Recuperación de la Memoria Histórica (http://memoriahistorica.org.es/category/s5-documentos/c46-libros-de-visitas/page/2/) es un recurso didáctico digital de gran utilidad para abordar la Memoria Histórica en clase. Elaborada por la propia Asociación para la Recuperación de la Memoria Histórica en 2018, esta web recopila las distintas exhumaciones llevadas a cabo por dicha asociación. De esta manera, recoge exhumaciones como las de Pravia - Agones (Asturias), Bañugues (Asturias), Guadalajara, Paramos - Val do Dubra (A Coruña), el cementerio de Ponferrada (León) o Alcalá del Valle (Cádiz).

De cada una de las exhumaciones se ofrece una exhaustiva información que incluye la fecha y el lugar donde fueron realizadas, la autoría de las mismas, el nombre y la historia de la fosa exhumada, la identidad (o posible identidad) y la historia de las víctimas que se espera encontrar en la fosa, la identidad de varios de los asistentes a la exhumación (sobre todo familiares de las víctimas inhumadas en la fosa) y los resultados de la exhumación.

Cabe destacar que cada exhumación cuenta con un enlace que dirige a un álbum de fotografías de la misma, el cual es el gran punto fuerte de este recurso, pues permite, mediante el visionado de estas fotografías (en muchas de las cuales aparecen los familiares de las víctimas observando las tareas de exhumación), empatizar y compartir la emoción de aquellos que, tantos años después, buscan ofrecer un 
entierro digno a sus familiares o amigos fallecidos. De esta manera, se logra que el alumnado conciba la Historia y el problema de la Memoria Histórica desde una perspectiva social y humana, echando a un lado la tan dominante visión política.

Sin embargo, este recurso muestra un aspecto en el que puede mejorar. Se trata, realmente, de una completa recopilación de exhumaciones llevadas a cabo por la Asociación para la Recuperación de la Memoria Histórica, pero sería recomendable que, en el álbum de fotografías de cada una de las exhumaciones, se incluyera, en cada fotografía, una descripción que informe acerca de lo que muestra la fotografía (qué tareas se están realizando, quiénes son las personas que aparecen en la imagen...). Se trata, pese a todo, de un detalle menor que no logra empañar la calidad de este recurso didáctico.

Finalmente, en cuanto a la utilidad curricular de este recurso didáctico en relación al currículo educativo del Bachillerato andaluz (el cual, como ya se ha mencionado, está regulado por el Real Decreto 1105/2014, de 26 de diciembre, del Gobierno de España y la Orden de 14 de julio de 2016 de la Junta de Andalucía) hay que destacar, en primer lugar, que permite profundizar en los contenidos de la Guerra Civil Española establecidos por dicho currículo para la asignatura Historia de España de $2^{\circ}$ de Bachillerato, abordando, entre las consecuencias del conflicto, el debate, de plena actualidad, de la Memoria Histórica y, con ello, fomentando una Historia social, humanizada y cercana a la realidad cotidiana del alumnado. Además, ayuda a cumplir uno de los criterios de evaluación ("analizar la Guerra Civil, identificando sus causas y consecuencias, la intervención internacional y el curso de los acontecimientos en las dos zonas", pues la Memoria Histórica es una consecuencia directa del desarrollo y resultado de la Guerra Civil) y uno de los estándares de aprendizaje ("especifica los costes humanos y las consecuencias económicas y sociales de la guerra”, pues el debate sobre la Memoria Histórica es también el debate acerca de la represión llevada a cabo por el bando sublevado durante la Guerra Civil) que el currículo educativo del Bachillerato andaluz establece para este tema.

Por otro lado, permite también alcanzar varios de los objetivos establecidos por el Real Decreto 1105/2014, de 26 de diciembre, del Gobierno de España para la etapa educativa de Bachillerato:

- "Ejercer la ciudadanía democrática, desde una perspectiva global, y adquirir una conciencia cívica responsable, inspirada por los valores de la Constitución española así como por los derechos humanos, que fomente la corresponsabilidad en la construcción de una sociedad justa y equitativa" (pues se presupone que el estudio de la Memoria Histórica, que busca la reparación de las víctimas de un conflicto a las que no se ha hecho justicia, fomente la defensa de los Derechos Humanos entre el alumnado y la búsqueda de una sociedad española más justa con dichas víctimas).

- "Consolidar una madurez personal y social que les permita actuar de forma responsable y autónoma y desarrollar su espíritu crítico. Prever y resolver pacíficamente los conflictos personales, 
familiares y sociales" (pues el debate, adecuadamente moderado por el docente, acerca de la Memoria Histórica fomentará entre el alumnado dicho espíritu crítico).

- "Fomentar la igualdad efectiva de derechos y oportunidades entre hombres y mujeres, analizar y valorar críticamente las desigualdades y discriminaciones existentes, y en particular la violencia contra la mujer e impulsar la igualdad real y la no discriminación de las personas por cualquier condición o circunstancia personal o social, con atención especial a las personas con discapacidad" (pues la represión llevada a cabo durante la Guerra Civil, abordada por la Memoria Histórica, es, al fin y al cabo, una forma de discriminación por motivos políticos e ideológicos).

- “Conocer y valorar críticamente las realidades del mundo contemporáneo, sus antecedentes históricos y los principales factores de su evolución. Participar de forma solidaria en el desarrollo y mejora de su entorno social" (pues el actual debate sobre la Memoria Histórica hunde sus raíces en la Guerra Civil y su abordaje resulta necesario para avanzar hacia una sociedad española más justa).

Este recurso, además, propicia el desarrollo, por parte del alumnado, de la Competencia Digital (pues el alumnado trabajará con un recurso digital a través del empleo de las Tecnologías de la Información y la Comunicación) y las Competencias Sociales y cívicas (pues el debate sobre la Memoria Histórica fomentará el desarrollo, en el alumnado, de un espíritu crítico y un sentimiento de responsabilidad con la mejora de la sociedad en la que vive).

Permite también cumplir los siguientes objetivos establecidos por la Orden de 14 de julio de 2016 de la Junta de Andalucía para la asignatura Historia de España de $2^{\circ}$ de Bachillerato:

- "Saber valorar las repercusiones que para la España presente han tenido los hechos que se estudian de su pasado" (pues, como ya se ha dicho, el actual debate sobre la Memoria Histórica es una consecuencia de la Guerra Civil).

- "Conocer y comprender la interrelación de los distintos acontecimientos tanto políticos, como sociales, económicos y culturales, valorando las causas, procesos y consecuencias para la situación actual" (pues la represión analizada por la Memoria Histórica sólo puede ser entendida en un contexto político, económico, social y cultural de guerra civil, siendo la Memoria Histórica, como se ha dicho anteriormente, una consecuencia actual de dicha represión).

- "Dominar las reglas democráticas de nuestro actual ordenamiento constitucional, valorando su proceso histórico y fomentando el compromiso individual y colectivo con los derechos humanos y las libertades. Conocer los problemas de índole social y económica fomentando el respeto a las normas de convivencia fundamentales, otorgadas en un devenir histórico lleno de sacrificios, trabajo y esfuerzos comunes" (pues la Memoria Histórica es un problema social fundamental, debiendo servir su estudio para fomentar el compromiso del alumnado con los valores de la libertad y los Derechos Humanos). 
Por último, cabe mencionar que este recurso didáctico permite cumplir con una de las estrategias metodológicas propuestas por la Orden de 14 de julio de 2016 de la Junta de Andalucía para la asignatura Historia de España de $2^{\circ}$ de Bachillerato: "convertir las herramientas digitales en un recurso básico para su impartición [de la Historia de España]”.

\section{2. Estudio del contenido de la web de exhumaciones de fosas comunes de la Asociación para la Recuperación de la Memoria Histórica}

En el presente subapartado, se expondrá el instrumento elaborado para analizar el contenido de un recurso didáctico concreto sobre la Guerra Civil (en este caso, la web de exhumaciones de fosas comunes de la Asociación para la Recuperación de la Memoria Histórica) y dicho instrumento será aplicado a este recurso para comprobar su validez.

Existen distintos métodos para medir el posicionamiento ideológico, entre los que cabe destacar el Gráfico de Nolan, creado en 1969 por el político estadounidense David Nolan, que define la posición ideológica de una persona en función de su opinión sobre distintos temas económicos y sociales. Así, se genera un sistema cartesiano de las ideologías políticas (progresista, liberal, conservador, autoritario o de centro). Lo cierto es que el Gráfico de Nolan alcanzó una gran popularidad en Estados Unidos en los años setenta y ochenta del siglo pasado. De hecho, se crearon, en dicho país, muchos test basados en él (Antena 3, 19 de junio 2018). Sin embargo, no puede ser aplicado a un recurso didáctico.

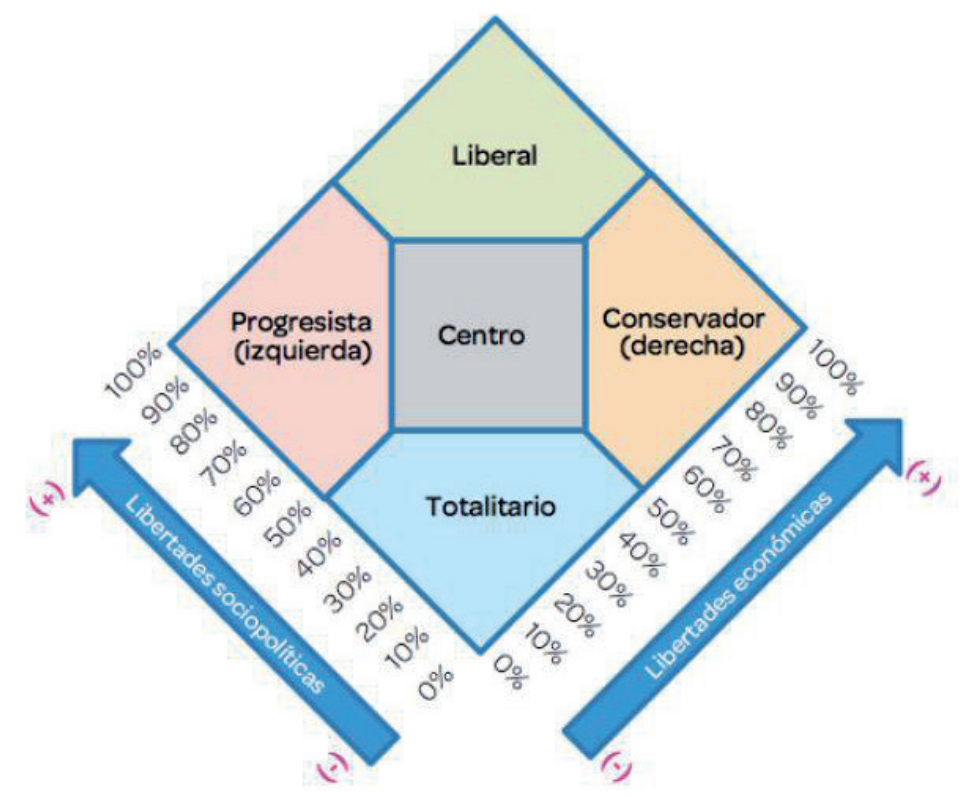

Figura 1. Representación del Gráfico de Nolan. Fuente: Antena 3, 2018 (recuperado de: http://www.antena3. com/liopardo/cuestionarios/test-politico-cual-es-tu-posicion-ideologica-segun-el-diagrama-de-nolan 201705105a94e3620cf2052ee3bdd80f.html) 
Por otra parte, cabe destacar las rúbricas, documentos usados con mucha frecuencia que describen los criterios seguidos para evaluar una tarea o producto, enumeran los niveles de calidad de cada uno de estos criterios con los parámetros que deben cumplir y añaden los puntos establecidos para cada nivel de calidad y la importancia o peso de cada criterio (García-Barrera, 2016).

Ejemplos de rúbricas aplicables a recursos didácticos son la rúbrica para evaluar Recursos Educativos Abiertos (desarrollados y compartidos de forma gratuita y pública) de TEMOA (portal de Recursos Educativos Abiertos), que usa como criterios la calidad del contenido, la motivación, el diseño y la presentación, la usabilidad, la accesibilidad, el valor educativo y la valoración global (Burgos, 19 de junio 2018), y la rúbrica LORI - AD, instrumento que permite medir la calidad de los recursos educativos digitales durante sus fases de diseño, desarrollo y post-implementación usando como criterios de evaluación la calidad del contenido, la correspondencia con el objetivo o competencia a desarrollar, la retroalimentación y adaptación, la motivación, el diseño y presentación, la interacción y usabilidad, la accesibilidad, la reusabilidad y el cumplimiento de normas (Adame, 2013). Otro ejemplo es la rúbrica elaborada por personal de la Universidad Complutense de Madrid para evaluar la calidad de los materiales educativos digitales, usando para ello como criterios de evaluación el cumplimiento de objetivos y coherencia didáctica, la calidad de los contenidos, la capacidad de generar aprendizaje, la adaptabilidad e interactividad, la motivación, el formato y diseño, la usabilidad, la accesibilidad, la reusabilidad y la interoperatividad (Domínguez, Fernández-Pampillón \& De Armas, 2013). No obstante, ninguna de las rúbricas mencionadas aborda de manera explícita la postura ideológica de los recursos didácticos evaluados.

De todo lo anterior se deduce la necesidad de proponer, en función de las problemáticas asociadas al análisis del contenido de los recursos didácticos de la Guerra Civil, un instrumento que permita el mismo, consistiendo el expuesto en este artículo en analizar dicho contenido atendiendo a los siguientes parámetros: mayor o menor presencia de recursos de uno y otro bando, posicionamiento ideológico de la fuente que aporta el recurso, uso del lenguaje efectuado por el recurso, realización o no de apologías de uno u otro bando por el recurso, mayor o menor uso de imágenes de uno u otro bando, justificación del propio recurso, personalidades de uno u otro bando mencionadas por el recurso, posible aparición de logos o símbolos de uno u otro bando en el recurso, posicionamiento ideológico del recurso con respecto a la Guerra Civil, potencialidad del recurso para propiciar la reflexión curricular en el aula e implicaciones del recurso para la profesionalidad docente.

A continuación, se aplica el instrumento anteriormente expuesto al recurso didáctico digital de la web de exhumaciones de fosas comunes de la Asociación para la Recuperación de la Memoria Histórica analizado en el subapartado anterior:

- Número de recursos de cada bando: se trata de un recurso que recoge únicamente información sobre exhumaciones de fosas comunes donde se encontraban represaliados del bando republicano. 
- Fuente: la autoría de este recurso corresponde a la Asociación para la Recuperación de la Memoria Histórica, surgida en octubre de 2000 como consecuencia de la exhumación de una fosa común en la que fueron encontrados los restos de trece civiles republicanos asesinados por falangistas, acudiendo a dicha exhumación numerosas personas que buscaban ayuda para encontrar a sus seres queridos represaliados y desaparecidos. Así, se decidió fundar la Asociación para la Recuperación de la Memoria Histórica con el objetivo de ofrecerles la ayuda que reclamaban.

La Asociación para la Recuperación de la Memoria Histórica cuenta con un numeroso equipo de trabajadores voluntarios, compuesto por familiares, profesionales procedentes de distintos ámbitos (arqueólogos, antropólogos, historiadores, documentalistas...) e, incluso, estudiantes (Asociación para la Recuperación de la Memoria Histórica, 22 de junio 2018b).

- Justificación del recurso: este recurso no ofrece justificación alguna para su elaboración.

- Uso del lenguaje: este recurso utiliza un lenguaje neutral a la hora de describir las exhumaciones realizadas por la Asociación para la Recuperación de la Memoria Histórica. Sin embargo, a la hora de explicar la historia de esta asociación (en el apartado titulado “¿Quiénes somos?”), se afirma que dicha asociación cumple con una función que el Estado español no ha sido capaz de desempeñar desde que la democracia volvió a España: ayudar a las familias que lo reclamen a recuperar los restos de sus desaparecidos en la Guerra Civil o la Dictadura franquista. De esta manera, el recurso denuncia la aprobación, tras la muerte de Franco en 1975, de la Ley de Amnistía (1977), que ofrecía amnistía a los delitos de agentes del orden público contra los Derechos Humanos cometidos antes del 15 de diciembre de 1976 (Asociación para la Recuperación de la Memoria Histórica, 22 de junio 2018b).

Además, hay que destacar el uso, por este recurso, de otro tipo de lenguaje: la imagen. Así, recoge álbumes fotográficos de las distintas exhumaciones llevadas a cabo, lo que facilita la empatía con los seres queridos de los represaliados en la Guerra Civil y la Dictadura mediante la visualización de imágenes cotidianas de las exhumaciones, en las que aparecen también dichos seres queridos.

- Apologías de uno u otro bando: este recurso no realiza ninguna apología de estas características.

- Imágenes de uno y otro bando: todas las imágenes de este recurso corresponden a las exhumaciones que recoge, por lo que dichas imágenes son relativas al bando republicano.

- Personalidades de uno y otro bando mencionadas: este recurso no menciona a ninguna personalidad de la Guerra Civil.

- Logos o símbolos presentes en el recurso: el único logo que aparece en este recurso se encuentra en el propio símbolo de la Asociación para la Recuperación de la Memoria Histórica, el cual muestra los colores de la bandera republicana (rojo, amarillo y morado). 
- Posicionamiento ideológico respecto a la Guerra Civil: se trata de un recurso didáctico que aborda la Guerra Civil desde una perspectiva favorable al bando republicano. Es cierto que no realiza apología alguna de dicho bando y que el hecho de que sólo recoja exhumaciones de fosas con víctimas republicanas se explica por la desatención de la Dictadura franquista hacia las mismas, centrándose ésta en las víctimas del bando rebelde (Gutiérrez \& Altozano, 2 de octubre 2008), por lo que, muy probablemente, habrá más víctimas de la represión sublevada en las fosas.

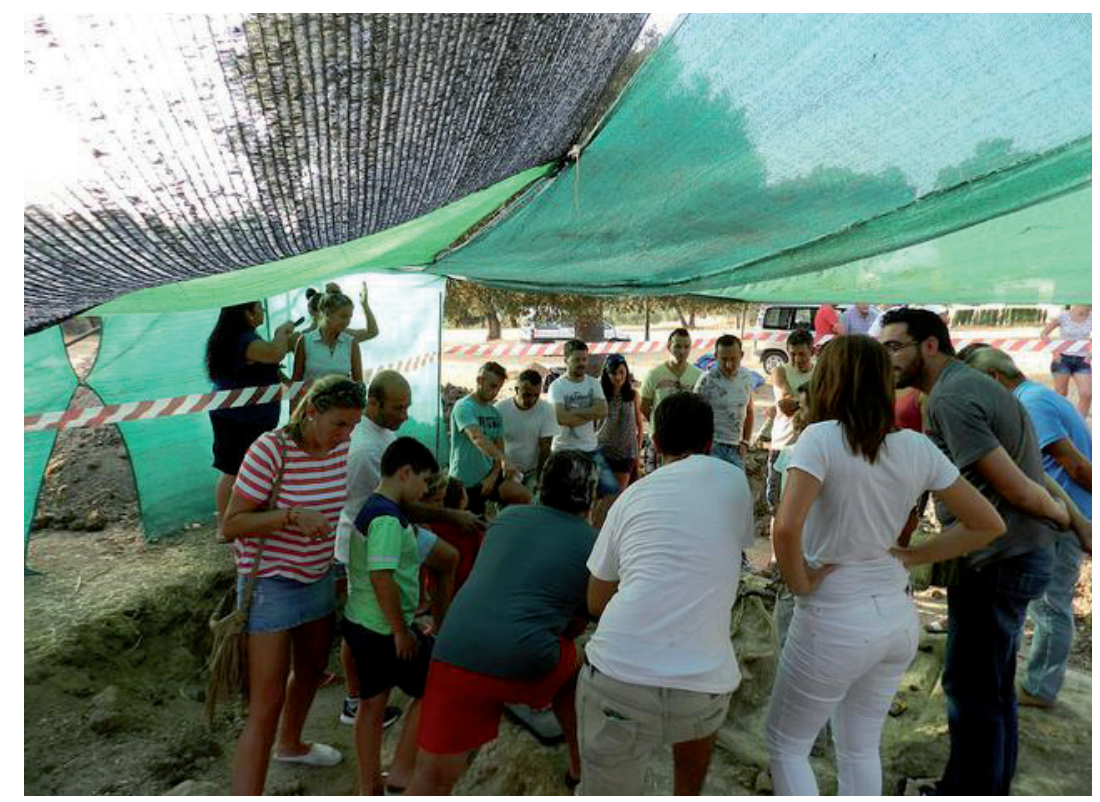

Fotografía 2. Fotografía perteneciente al álbum fotográfico de la exhumación de una fosa común por la Asociación para la Recuperación de la Memoria Histórica en el cortijo El Baldío (Alcalá del Valle, Cádiz, España).

Fuente: Asociación para la Recuperación de la Memoria Histórica, 2015 (recuperado de: https://www.flickr.com/photos/memoriahistorica/20323313130/in/album-72157656727424959/)

Sin embargo, su elaboración por parte de la Asociación para la Recuperación de la Memoria Histórica, que lleva en su propio símbolo los colores de la bandera republicana, y el uso de un lenguaje que critica la amnistía concedida por el Estado español tras la muerte de Franco a los crímenes de lesa humanidad cometidos en la Guerra Civil y bajo su dictadura, evidencian un posicionamiento favorable al bando republicano y la reparación de sus represaliados.

- Potencialidad para propiciar la reflexión curricular en el aula: en la medida en que este recurso ofrece una Historia social de la Guerra Civil, pues se centra en la cuestión de las víctimas represaliadas por el bando sublevado y las consecuencias de dicha represión en la sociedad española actual (con numerosas víctimas aún en fosas comunes), permite reflexionar acerca de la necesidad de dar más peso a este tipo de Historia, especialmente a la hora de abordar conflictos bélicos, acerca de los cuales tienden a predominar las interpretaciones historiográficas centradas en los aspectos políticos y militares. 
Además, el polémico tema de la Memoria Histórica de la Guerra Civil, de plena actualidad en España, permite la reflexión acerca de la necesidad de fomentar el debate (adecuadamente moderado por el docente) en clase de Historia, para lograr el desarrollo, por parte del alumnado, de un espíritu de razonamiento crítico que, además, le permita compartir ideas con otras personas de forma respetuosa y coherente.

- Implicaciones para la profesionalidad docente: en relación con lo anterior, destacar que este recurso permite al profesorado adoptar un enfoque que presta más atención a la Historia social, a menudo eclipsada por la Historia política y militar en la historiografía tradicional (sobre todo en lo tocante a conflictos bélicos), introduciendo además el debate crítico, siempre necesario para huir de interpretaciones estáticas y categóricas de los relatos historiográficos, en el aula mediante las posibilidades que para ello brinda un tema de plena actualidad como la Memoria Histórica de la Guerra Civil. De hecho, la actualidad de este tema ofrece al docente la oportunidad de plantear al alumnado la Guerra Civil (y, en general, la propia Historia) como una realidad cercana a su entorno cotidiano.

\section{Conclusiones}

En primer lugar, cabe destacar que el análisis de las características y utilidades curriculares del recurso didáctico digital seleccionado en este trabajo (la web de exhumaciones de fosas comunes de la Asociación para la Recuperación de la Memoria Histórica) ha llevado a la conclusión de que dicho recurso cumple diversas funciones de gran importancia para abordar la enseñanza de la Guerra Civil en Bachillerato. Ejemplos de estas funciones son el aumento del peso de la Historia social y cultural frente al tradicional dominio de la Historia política y militar a la hora de abordar conflictos bélicos como la Guerra Civil o el acercamiento de este conflicto a la realidad del alumnado. Permite también desarrollar la Competencia Digital (pues el alumnado trabaja con herramientas digitales) y las Competencias Sociales y Cívicas (mediante el debate acerca de la Memoria Histórica de la Guerra Civil que puede ser propiciado con el uso de este recurso didáctico). Y, lo que es más importante desde el punto de vista del currículo educativo del Bachillerato andaluz, permite cumplir con elementos del mismo como criterios de evaluación, estándares de aprendizaje, objetivos (tanto de la etapa del Bachillerato como de asignaturas con presencia de la Guerra Civil) u orientaciones metodológicas. Por tanto, la respuesta a la pregunta de si el recurso didáctico recogido en este trabajo es útil en relación al currículo educativo andaluz de Bachillerato es, ciertamente, afirmativa.

En esta línea, hay que recordar ahora los otros dos objetivos específicos planteados al comienzo de este artículo: analizar el modelo de profesionalidad docente y el potencial para el desarrollo profesional del profesorado que ofrece el recurso didáctico seleccionado en esta investigación y comprobar si dicho 
recurso propicia un aprendizaje significativo y adaptado a las posibilidades e intereses del alumnado. En cuanto al primero de ellos, destacar que el recurso seleccionado en esta investigación fomenta un modelo de profesionalidad docente basado en la reivindicación de la importancia de la Historia social y cultural a la hora de abordar un determinado período histórico (en este caso, la Guerra Civil) y el fomento del debate crítico y razonado entre el alumnado (con la adecuada labor de moderación del profesor) acerca de la Memoria Histórica de la Guerra Civil. Ello permitirá un desarrollo profesional del docente (aunque el recurso en cuestión no aluda de forma explícita al mismo) hacia una enseñanza que entienda la Historia como una disciplina cambiante y en continua revisión, basada en el razonamiento crítico y cercana a los problemas de la realidad en la que vive el alumnado y un análisis de su propia práctica docente para incorporar, usando como herramienta el recurso seleccionado, todos estos elementos a la misma de la forma más adecuada. Por tanto, el profesorado desarrolla un modelo curricular que da una gran importancia al proceso de aprendizaje frente a la simple obtención de resultados.

En segundo lugar, la investigación lleva a la conclusión de que el recurso seleccionado fomenta un aprendizaje significativo por parte del alumnado (poniendo en relación lo aprendido sobre la Guerra Civil con los temas de la represión y la Memoria Histórica de la misma, los cuales, en definitiva, son consecuencias del conflicto). De hecho, el alumnado podrá incluso relacionar lo aprendido sobre la represión durante el conflicto con la información que recibe desde su realidad cotidiana, en la cual la Memoria Histórica es un tema de plena vigencia. Esta relación de la Guerra Civil con el entorno cotidiano del alumnado que propicia este recurso didáctico aumenta, precisamente, las posibilidades de que el alumnado muestre un mayor interés por dicho tema. Además, se trata de un recurso perfectamente adaptado a las posibilidades del alumnado de Bachillerato, que puede manejarlo perfectamente.

Por otro lado, en lo que respecta al instrumento elaborado y planteado en este trabajo, éste nos permite, mediante la consideración, para un recurso didáctico digital de la Guerra Civil en concreto, de los once parámetros que lo componen, analizar el contenido del mismo de forma rigurosa y fundamentada, tal y como demuestra su aplicación al recurso analizado en este trabajo. De esta manera, las preguntas de cómo se puede analizar de forma adecuada el contenido de los recursos didácticos de la Guerra Civil y de si es válido el instrumento expuesto en este trabajo quedan satisfactoriamente respondidas.

Sin embargo, es necesario hacer dos aclaraciones. En primer lugar, no hay que perder de vista que el instrumento de análisis propuesto por este trabajo tiene un carácter orientativo, por lo que no es un instrumento que deba ser considerado infalible e inamovible. Por tanto, puede y debe ser revisado y es susceptible de sufrir modificaciones basadas en el rigor por parte de todos aquellos investigadores que las consideren necesarias. De hecho, el carácter orientativo de este instrumento viene remarcado por el hecho de que cada uno de los parámetros que lo componen y sobre los que se analiza el contenido de cada recurso tendrá mayor o menor relevancia a la hora de llevar a cabo dicho análisis según con qué 
recurso se esté trabajando. Así, por ejemplo, si un recurso carece de imágenes, el parámetro referido a las imágenes de uno y otro bando de la Guerra Civil que aparecen en el recurso no deberá ser considerado.

En segundo lugar, hay que volver a una de las preguntas planteadas al comienzo de este artículo: ¿el hecho de que un recurso no sea totalmente neutral respecto a la Guerra Civil convierte su uso en poco recomendable? Lo cierto es que la situación planteada en el interrogante no conlleva que dicho recurso no deba ser empleado en la práctica docente. La clave para seleccionar un recurso o no debe radicar en el rigor con que dicho recurso aborde el tema de la Guerra Civil en cuestión. Así, el recurso de la web de exhumaciones de fosas comunes de la Asociación para la Recuperación de la Memoria Histórica muestra un posicionamiento ideológico favorable al bando republicano, pues es elaborado por la Asociación para la Recuperación de la Memoria Histórica (cuyo propio logo lleva los colores de la bandera de la II República, lo cual es una declaración de intenciones) y utiliza un lenguaje que critica la amnistía otorgada por el Estado español, tras la muerte de Franco en 1975, a los crímenes de lesa humanidad cometidos durante la Guerra Civil y su posterior dictadura. Sin embargo, este recurso no hace apología alguna de ninguno de los dos bandos contendientes en la Guerra Civil y es riguroso criticar una amnistía que olvidó la persecución sufrida por los republicanos en esta guerra y la posterior Dictadura franquista y actuar defendiendo una causa como la de la Memoria Histórica, que busca la reparación de unas víctimas que, por motivos políticos, no pudieron ser reconocidas durante la Dictadura franquista posterior a la Guerra Civil (Gutiérrez \& Altozano, 2 de octubre 2008; Rengel, 27 de diciembre 2017). Todo ello, unido al hecho de que se trata de un recurso didáctico muy completo, hace que su aplicación en el aula sea más que recomendable.

\section{Referencias bibliográficas}

Adame, S. I. (2013). Instrumento para evaluar recursos educativos digitales, LORI-AD. Revista CERTUS. Universidad Autónoma de Guadalajara, 12, 56-67. Recuperado de: http:// genesis.uag.mx/certus/vol12/lori.cfm

Antena 3 (2018). Diagrama de Nolan [Gráfico]. Recuperado de: http://www.antena3.com/liopardo/ cuestionarios/test-politico-cual-es-tu-posicion-ideologica-segun-el-diagrama-de-nolan 201705105a94e3620cf2052ee3bdd80f.html

Antena 3. Test político: ¿cuál es tu posición ideológica según el diagrama de Nolan? Líopardo. http://www.antena3.com/liopardo/cuestionarios/test-politico-cual-es-tuposicion-ideologica-segun-el-diagrama-denolan 201705105a94e3620cf2052ee3bdd80f.html [Consultado 19/06/2018]. 
Asociación para la Recuperación de la Memoria Histórica (2015). Alcalá del Valle-El Baldío (Cádiz) (22) [Fotografía]. Recuperado de: https://www.flickr.com/photos/memoriahistorica/20323313130/in/album-72157656727424959/

Asociación para la Recuperación de la Memoria Histórica. Exhumaciones. Asociación para la Recuperación de la Memoria Histórica. http://memoriahistorica.org.es/category/s5-documentos/c46-libros-de-visitas/page/3/[Consultado 22/06/2018a].

Asociación para la Recuperación de la Memoria Histórica. ¿Qué es la Asociación para la Recuperación de la Memoria Histórica (ARMH)? . Asociación para la Recuperación de la Memoria Histórica. http://memoriahistorica.org.es/que-es-la-asociacion-para-la-recuperacion-de-la-memoria-historica-armh-2000-2012/ [Consultado 22/06/2018b].

Burgos, J. V. Rúbricas para evaluar Recursos Educativos Abiertos (REA). TEMOA: Open Educational Resources Portal. http://www.temoa.info/sites/default/files/OER_Rubrica.pdf [Consultado 19/06/2018].

Domínguez, E., Fernández-Pampillón, A. \& De Armas, I. (2013). Rúbrica para evaluar la calidad de los Materiales Educativos Digitales [Rúbrica]. Recuperado de: eprints.ucm. es/12533/2/Rúbrica calidad MED 2013 (2).pdf

Feliu, M. \& Hernàndez, F. X. (2013). Didáctica de la Guerra Civil española. Barcelona: Editorial Graó.

García-Barrera, A. (2016). Evaluación de recursos tecnológicos didácticos mediante e-rúbricas. RED. Revista de Educación a Distancia, 49 (13). Recuperado de: http://www.um.es/ ead/red/49/garcia-barrera.pdf

Gutiérrez, V. \& Altozano, M. (2 de octubre 2008). Madrid reúne datos sobre cientos de enterrados en fosas de ambos bandos. El País. Recuperado de: https://elpais.com/diario/2008/10/02/ espana/1222898401_850215.html

Orden de 14 de julio de 2016, por la que se desarrolla el currículo correspondiente al Bachillerato en la Comunidad Autónoma de Andalucía, se regulan determinados aspectos de la atención a la diversidad y se establece la ordenación de la evaluación del proceso de aprendizaje del alumnado. Boletín Oficial Junta de Andalucía, no 145, 29-07-2016.

Real Decreto 1105/2014, de 26 de diciembre, por el que se establece el currículo básico de la Educación Secundaria Obligatoria y del Bachillerato. Boletín Oficial del Estado, $n^{\circ} 3$, 03-01-2015. 
Rengel, C. (27 de diciembre 2017). 10 años de la Ley de Memoria Histórica: ni verdad, ni justicia ni reparación. Huffington Post. Recuperado de: https://www.huffingtonpost. es/2017/12/26/10-anos-de-la-ley-de-memoria-historica-ni-verdad-ni-justicia-nireparacion a $23316863 /$

Saenz del Castillo, A. (2015). El mapa de fosas del País Vasco. Un recurso didáctico de la arqueología del conflicto basado en las TIC. Revista de Didácticas Específicas, 12, 117-135. Recuperado de: https://revistas.uam.es/didacticasespecificas/article/download/didacti$\underline{\operatorname{cas} 2015.12 .006 / 998}$

Sánchez, J., Ruiz, J. \& Gómez, M. (2016). Tecnologías de la comunicación y la información aplicadas a la educación. Madrid: Síntesis.

Sociedad de Ciencias Aranzadi (s. f.). Personas observando los esqueletos de la fosa [Fotografía]. Recuperado de: http://www.aranzadi.eus/antropologia-fisica/memoria-historica 